\title{
Research Paper \\ Psychometric properties of the persian version of international trauma questionnaire (itq) in iranian women
}

\begin{abstract}
Citation: Benrazi Ghabeshi M, Farah Bijari A, Dehshiri Gh, Mehrinejad S.A. Psychometric properties of the persian version of international trauma questionnaire (itq) in iranian women. $\mathbf{J}$ of Psychological Science. 2022; 20(108): 2181-2194.
\end{abstract}

Mina Benrazi Ghabeshi ${ }^{1}$, Azam Farah Bijari ${ }^{2}$, Gholamreza Dehshiri ${ }^{3}$, Seyed Abolghasem Mehrinejad ${ }^{3}$

1. Ph.D Student in Psychology, Faculty of Educational Sciences and Psychology Alzahra University, Tehran, Iran.

2. Assistant Professor, Department of Psychology, Faculty of Educational Sciences and Psychology, Alzahra University, Tehran, Iran 3. Associate Professor, Department of Psychology, Faculty of Educational Sciences and Psychology, Alzahra University, Tehran,
URL: https://psychologicalscience.ir/article-1-1271-fa.html
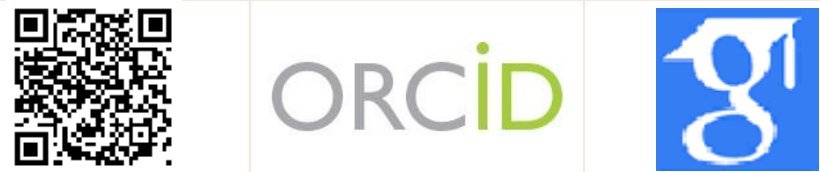

$\underline{10.52547 / J P S .20 .108 .2181}$
A R T I C L E I N F O

\section{A B S T R A C T}

Keywords:

International Trauma,

Questionnaire,

Trauma,

Psychometric properties,

Persian version

Received: 21 May 2021

Accepted: 20 Jun 2021

Available: $20 \mathrm{Feb} 2022$
Background: The World Health Organization recently released the 11th revision of the International Classification of Diseases with the inclusion of Complex Posttraumatic Stress Disorder (CPTSD). ICD-11 construed CPTSD as a disorder comprising of posttraumatic stress disorder (PTSD) and disturbance of self-organization (DSO) domains. In order to have a CPTSD diagnosis, PTSD subdomains (reexperiencing, avoidance, and threat) and DSO subdomains (affective dysregulation, negative self-concept, and interpersonal relationship difficulties) need to be satisfied. Despite the emerging research examining the symptom structure of CPTSD, to date, none so far have reached consensus on what best represents CPTSD.

Aims: The purpose of this study was to prepare a Persian version of the International Trauma Questionnaire (ITQ) and to examine its psychometric properties among Iranian women.

Methods: 259 people were selected using the convenience sampling method and completed the Persian version of International Trauma Questionnaire. Data were analyzed using Cronbach's alpha indices, composite reliability and confirmatory factor analysis.

Results: Cronbach's alpha coefficient for PTSD was 0.83 and for DSO was 0.81 and the combined reliability of the test was more than 0.8 . The results of confirmatory factor analysis showed that the factor load of the items is more than 0.4 and the scale has good construct validity.

Conclusion: Given the desirable psychometric properties of the Persian version of the International Trauma Questionnaire, its use can be recommended to experts in the field of psychology in research and diagnostic situations.

* Corresponding Author: Azam Farah Bijari, Assistant Professor, Department of Psychology, Faculty of Educational Sciences and Psychology, Alzahra University, Tehran, Iran.

E-mail: a.f.bidjari@alzahra.ac.ir

Tel: (+98) 9127223481

2476-5740/ (C) 2021 The Authors. This is an open access article under the CC BY-NC-ND license

(https://creativecommons.org/licenses/by-nc/4.0/). 


\section{Extended Abstract}

\section{Introduction}

Two "sibling disorders" have been proposed for the 11th version of the International Classification of Diseases (ICD-11): posttraumatic stress disorder (PTSD) and complex PTSD (CPTSD) (Karatzias et al., 2017). The ICD-11 model of PTSD includes six symptoms measuring three clusters (each cluster is composed of two symptoms): (1) re-experiencing of the trauma in the present (Re), (2) avoidance of traumatic reminders (Av), and (3) a persistent sense of threat that is manifested by increased arousal and hypervigilance (Th). The ICD-11 model of CPTSD is composed of six symptom clusters: three are shared with PTSD and three that are collectively referred to as "disturbances in self-organization" (DSO): affective dysregulation (AD), negative self-concept (NSC), and disturbed relationships (DR). CPTSD is conceptualized as a broader diagnosis recognizing the pervasive psychological damage that may result from sustained, repeated, and multiple forms of traumatic exposures (e.g., childhood abuse, domestic violence; political imprisonment) (Brewin et al., 2017). International Trauma Questionnaire (ITQ: Cloitre, Roberts, Bisson, \& Brewin, 2015), a selfreport measure specifically designed to capture the ICD-11 symptoms of PTSD and DSO. To date, the extant research evidence appears to support the construct validity of the ICD-11's proposals for PTSD and CPTSD. (Cloitre, Garvert, Brewin, Bryant, \& Maercker, 2013; Hyland et al., 2017a, 2017b; Hyland, Brewin, \& Maercker, 2017d; Karatzias et al., 2017; Knefel \& Lueger-Schuster, 2013; Nickerson et al., 2016; Shevlin et al., 2017; Tay et al., 2017).

The current study aimed to prepare a Persian version of the International Trauma Questionnaire (ITQ) and use CFA to test the factorial validity of CPTSD, acknowledging the delineation between the hyperand hypoactivation symptoms of AD among Iranian women.

\section{Method}

In this study, cross-sectional descriptive research design and correlational research were used. sample consist of 259 normal women and girls, were selected by available sampling method from Iranian women and girls. Subjects were assessed by the Persian version of International Trauma Questionnaire. Data were analyzed using Cronbach's alpha indices, composite reliability and confirmatory factor analysis. Data were analyzed by using SPSS-26 and AMOS-24 software.

\section{Results}

In the research sample, $35.9 \%$ were in the age group of 17 to 30 years, $46.7 \%$ were in the age group of 31 to 45 years and $17.4 \%$ were in the age group of 46 to 65 years. In terms of marital status, $41.7 \%$ were single, $51.7 \%$ were married, $5.4 \%$ were divorced and $1.2 \%$ were widows. In terms of education, $36.6 \%$ had undergraduate and graduate degrees, $47.1 \%$ had a bachelor's degree and $16.6 \%$ had a master's degree or higher.

First of all, Cronbach's alpha was used to determine the reliability of the questionnaire. Composite reliability was also used, which is an alternative to Cronbach's alpha in structural equation model analysis (Esposito Venice, China, Hensler, Wang, 2010). Cronbach's alpha coefficient for the first factor (PTSD) was 0/83, the second factor (DSO) was 0.81 and for composite reliability coefficient (CR) was 0.86 (Table 1).

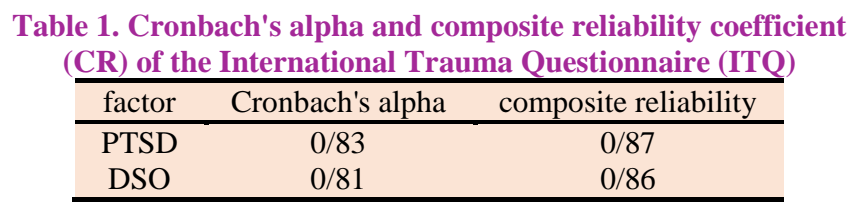

After that confirmatory factor analysis were used to test the factorial validity of CPTSD, acknowledging the delineation between the hyper and hypoactivation symptoms as two separate affect dysregulation factors. Model fit statistics for the ITQ are presented in Table 2. Model has acceptable goodness-of-fit indices, with chi-squared to degrees of freedom ratios $<3: 1$ indicating acceptable model fit; RMSEA levels $<.08$ that was above the criteria for acceptable model fit and CFI/TLI > 0.90 indicating excellent fit. Considering all indices together, Model appears to offer a viable representation of the latent structure of the ITQ. (Table 2). Standardized factor loadings for model are also displayed in Table 3. 
Table 2. Model fit statistics for model of the ITQ

\begin{tabular}{cccccccccc}
\hline RMSEA & NFI & IFI & TLI & CFI & $X^{2} / \mathrm{df}$ & P & df & $X^{2}$ \\
\hline $0 / 059$ & $0 / 87$ & $0 / 93$ & $0 / 92$ & $0 / 93$ & $1 / 90$ & $0 / 0001$ & 200 & $380 / 437$ \\
\hline
\end{tabular}

Table 3. Standardized factor loadings for model

\begin{tabular}{|c|c|c|c|c|}
\hline Factos & Items & $\begin{array}{l}\text { Standardized } \\
\text { factor loadings }\end{array}$ & $\begin{array}{c}\text { critical } \\
\text { points }\end{array}$ & $\mathrm{P}$ \\
\hline \multirow{5}{*}{ PTS } & $\begin{array}{c}\text { Having upsetting dreams that replay part of the experience or are clearly } \\
\text { related to the experience. }\end{array}$ & $0 / 70$ & $8 / 84$ & $0 / 0001$ \\
\hline & $\begin{array}{l}\text { Having powerful images or memories that sometimes come into your mind } \\
\text { in which you feel the experience is happening again in the here and now. }\end{array}$ & $0 / 85$ & $10 / 56$ & $0 / 0001$ \\
\hline & $\begin{array}{l}\text { Avoiding internal reminders of the experience (for example, thoughts, } \\
\text { feelings, or physical sensations). }\end{array}$ & $0 / 79$ & $7 / 21$ & $0 / 0001$ \\
\hline & $\begin{array}{l}\text { Avoiding external reminders of the experience (for example, people, } \\
\text { places, conversations, objects, activities, or situations). }\end{array}$ & $0 / 73$ & $6 / 65$ & $0 / 0001$ \\
\hline & Being "super-alert", watchful, or on guard. & $0 / 69$ & $8 / 47$ & $0 / 0001$ \\
\hline \multirow{17}{*}{ DSO } & Feeling jumpy or easily startled. & $0 / 76$ & $9 / 81$ & $0 / 0001$ \\
\hline & I react intensely to things that don't seem to affect other people so much. & $0 / 71$ & $9 / 32$ & $0 / 0001$ \\
\hline & When I am upset, it takes me a long time to calm down. & $0 / 63$ & $8 / 68$ & $0 / 0001$ \\
\hline & My feelings tend to be easily hurt. & $0 / 55$ & $7 / 61$ & $0 / 0001$ \\
\hline & I experience episodes of uncontrollable anger. & $0 / 64$ & $8 / 72$ & $0 / 0001$ \\
\hline & I do things that people have told me are dangerous or reckless. & $0 / 44$ & $6 / 21$ & $0 / 0001$ \\
\hline & I feel numb or emotionally shut down. & $0 / 70$ & $11 / 80$ & $0 / 0001$ \\
\hline & $\begin{array}{c}\text { I am the kind of person who has difficulty experiencing feelings of } \\
\text { pleasure or joy. }\end{array}$ & $0 / 67$ & $9 / 89$ & $0 / 0001$ \\
\hline & $\begin{array}{l}\text { When I am under stress or confronted with reminders of my trauma, I often } \\
\text { feel that the world is distant or that the world seems different. }\end{array}$ & $0 / 73$ & $12 / 15$ & $0 / 0001$ \\
\hline & $\begin{array}{l}\text { When I am under stress or confronted with reminders of my trauma, I often } \\
\text { feel outside my body or feel that there is something strange about my body. }\end{array}$ & $0 / 66$ & $9 / 84$ & $0 / 0001$ \\
\hline & I feel like a failure. & $0 / 86$ & $18 / 03$ & $0 / 0001$ \\
\hline & I feel worthless. & $0 / 84$ & $17 / 01$ & $0 / 0001$ \\
\hline & I often feel ashamed of myself whether it makes sense or not. & $0 / 87$ & $18 / 11$ & $0 / 0001$ \\
\hline & I feel guilty about things I have done or failed to do. & $0 / 83$ & $16 / 58$ & $0 / 0001$ \\
\hline & I feel distant or cut off from people. & $0 / 78$ & $11 / 69$ & $0 / 0001$ \\
\hline & I find it hard to stay emotionally close to people. & $0 / 82$ & $12 / 58$ & $0 / 0001$ \\
\hline & I avoid relationships because they end up being too difficult or painful. & $0 / 71$ & $11 / 01$ & 0/0001 \\
\hline
\end{tabular}

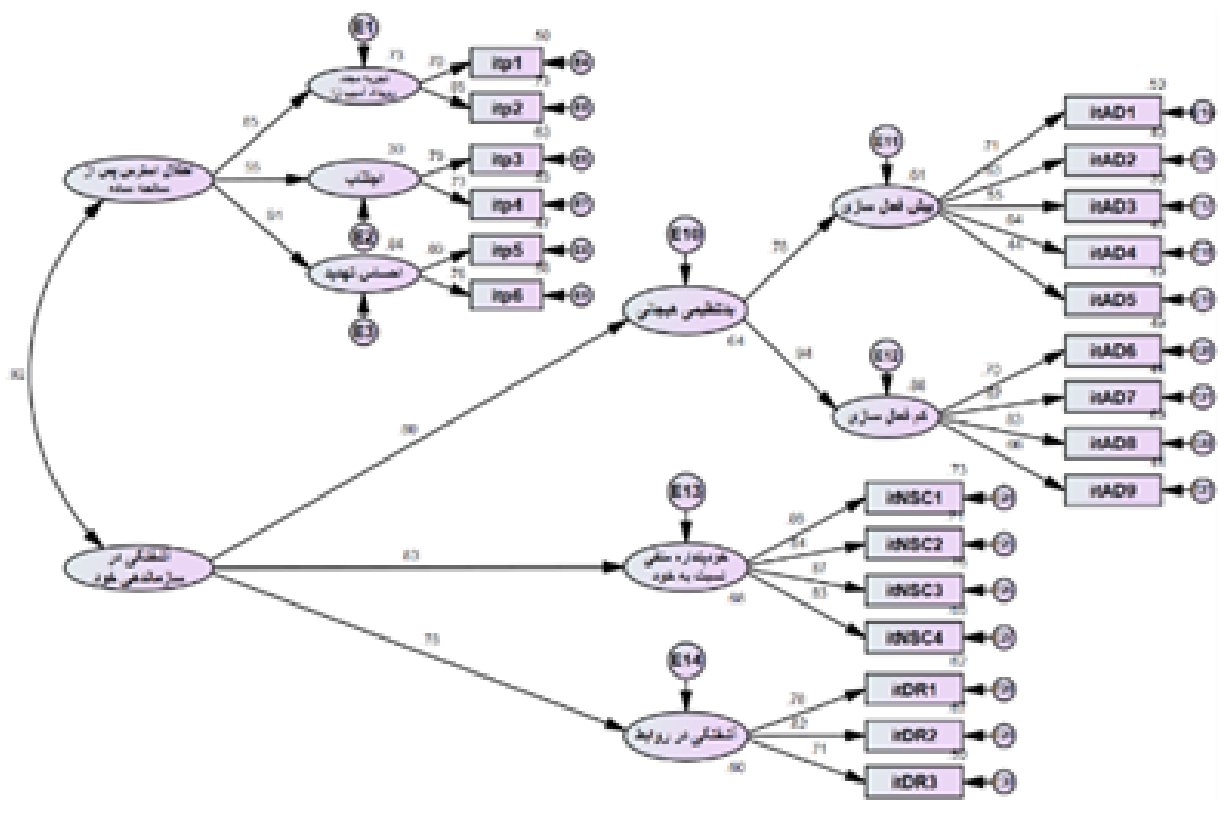

Figure 1. Two-factor model of International Trauma Questionnaire (ITQ) and standard coefficients of routes 
The results of examining the factor structure of PTSD and CPTSD showed that the second-order two-factor model with 7 first-order factors was the best fitting model. In Figure 1, the final confirmatory factor model of the International Trauma Questionnaire (ITQ) is reported.

\section{Conclusion}

As mentioned earlier, the present study was conducted to evaluate the structural validity of the International Trauma Questionnaire (ITQ) among a sample of normal women. The results of confirmatory factor analysis (CFA) provided new experimental support for PTSD / CPTSD based on ICD-11 diagnostic criteria. The results from the CFA indicated that a correlated first-order model with three latent variables ( $\mathrm{Re}, \mathrm{Av}$, and $\mathrm{Th}$ ) representing PTSD and four latent variables (Hy, Ho, NSC, and DR) representing DSO was the best fitting model. These results are consistent with much of the previous factor analytic work that has found that this model is generally the best fitting model (Hyland et al., 2017a, 2017c, 2017d; Karatzias et al., 2017; Nickerson et al., 2016; Shevlin, McElroy, Bentall, Reininghaus, \& Murphy, 2016; Tay et al., 2015). The important difference between this analysis and the previous research is that the dimensionality of the $\mathrm{AD}$ indicators was assessed. The results suggested that the hyperactivation and hypoactivation indicators were best represented by two correlated latent variables rather than one latent variable. It is clear that difficulties in emotional regulation are common consequences of trauma, particularly of an interpersonal typebut to date the $\mathrm{AD}$ cluster of symptoms has been considered to be a unitary construct. More recent research has examined the role of specific facets of emotional dysregulation and showed that there is specificity in the relationship between different types of trauma and specific types of difficulties in emotional regulation. This is important as it suggests that for a general measure of trauma response, such as the ITQ, the assessment of different aspects of emotional dysregulation (in this case hyperactivation and hypoactivation) is necessary when assessing CPTSD in populations who have been exposed to different, or multiple, forms of trauma. As a result, considering the desirable psychometric properties of the Persian version of the International Trauma Questionnaire, its use can be suggested to mental health professionals in research and diagnostic situations.

\section{Ethical Considerations}

Compliance with ethical guidelines: The authors extracted this article from the $\mathrm{PhD}$ dissertation of the first author, which approved under date, 26.06.2019 in the Department of Psychology, Faculty of Educational Sciences and Psychology, Alzahra University, Tehran, Iran. Ethical considerations like gaining the informed consent of the participants and the confidentiality of responses were considered in this research. Funding: This study was conducted as a $\mathrm{PhD}$ thesis with no financial support.

Authors' contribution: The first author was the senior author, the second and third were the supervisors and the forth was the advisor.

Conflict of interest: the authors declare no conflict of interest for this study.

Acknowledgments: I would like to appreciate the supervisors, the advisor, and all participants. 


\section{ويز حى هاى روانسنجى نسخه فارسى يرسشنامه بين المللى رويدادهاى آسيبزا (ITQ) دربين زنان ايرانى}

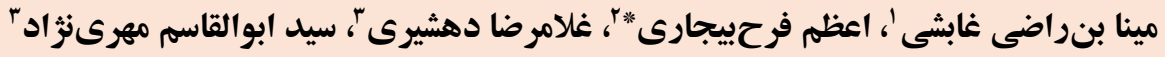

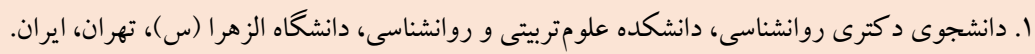

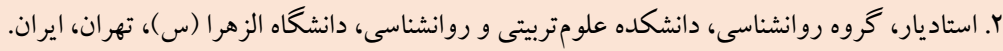

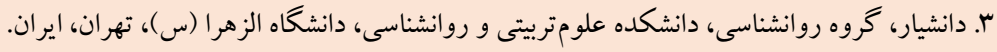

زمينه: سازمان جهانى بهداشت اخيراً يازدهمين نسخه تجديدنظر شده در طبقه بندى بيمارى ها را با گنجاندن اختلال تنيدگى بس ضربه اى

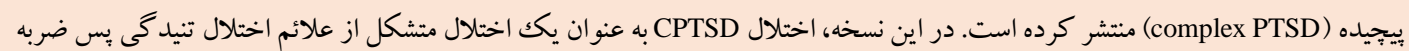
اى ساده (PTSD) و اختلال در سازماندهى خود (DSO) مطرح شد. به منظور تشخيص CPTSD، خرده مقياس هاى PTSD (شامل؛ تجربه مجدد، اجتناب و تهديد) و خرده مقياس هاى DSO (شامل؛ بد تنظيمى هيجانى، خودينداشت منفى و آشفتكى در روابط بين فردى) بايد وجود داشته باشد. با وجود تحقيقات در حال بررسى ساختار عاملى اين اختلال، تابه امروز، هيج تحقيقى در مورد بهترين معرف اختلال تنيد يس ضربه اى بييجيده به توافق نرسيده است. هدف: هدف ئزوهش حاضر، تهيه نسخه فارسى يرسشنامه بين الملى رويدادهاى آسيب زاو بررسى ويز گیى هاى روان سنجى آن در بين زنان ايرانى بود. روش: وها زن ايرانى با استفاده از روش نمونه گيرى در دسترس انتخاب شده و نسخه فارسى برسشنامه بين المللى رويدادهاى آسيب زا

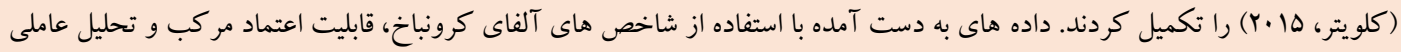
تأييدى تحليل شدند.

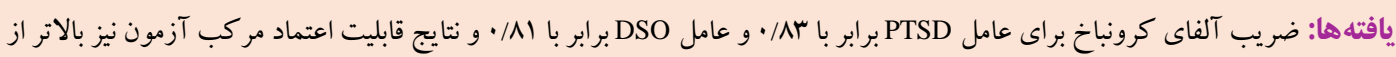

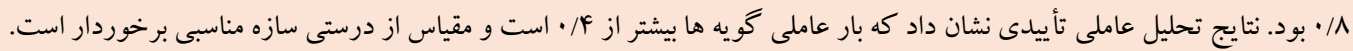
نتيجه كيرى: با توجه به مطلوب بودن خصوصيات روان سنجى نسخه فارسى برسشنامه بين المللى رويدادهاى آسيب زا، مى توان استفاده از آن را به متخصصان حوزه روان شناسى در موقعيت هاى يثوهشى و تشخيصى بيشنهاد كرد.
مشخصات مقاله

كليدوازهمها:

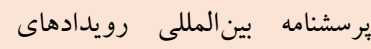
آسيبزا،

رويدادهاى آسيبزا،

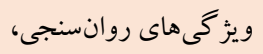
نسخه فارسى

* نويسنده مسئول: اعظم فرحبيجارى، استاديار، گروه روانشناسى، دانشكده علومتربيتى و روانشناسى، دانشگاه الزهرا (س)، تهران، ايران. رايانامه: 


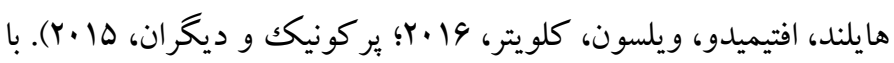

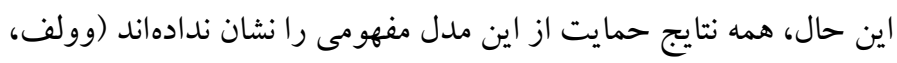

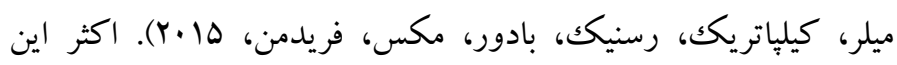

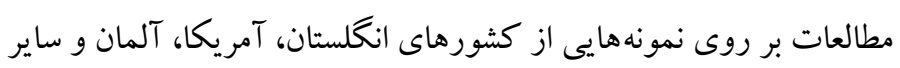

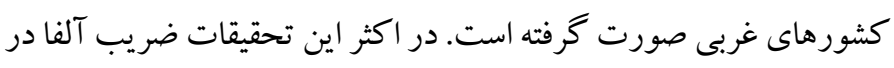

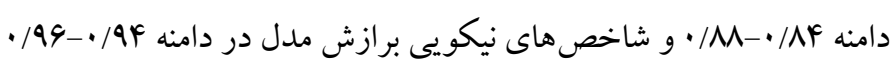
قرار داشتند. با توجه به اينكه هدف ICD-11 فراهم كردن استانداردهاى تشخيصى جهانى است بنابراين ضرورى مى باشد كه ابزارهاى اندازه گيرى مورد استفاده محققان و متخصصان بالينى در نمونههاى مختلف فرهنى بنى بنى داراى اعتبار باشند. با توجه به اهميت اين موضوع و لحاظ اين مسأله كه در ايران تا به امروز مطالعهاى در رابطه با اختلال CPTSD و درستى سازه اين اختلال انجام نشده است، نياز به تحقيقات بيشترى در اين زمينه وجود دارد. همجينين تحقيقاتى

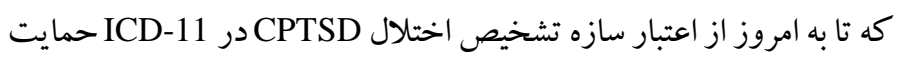

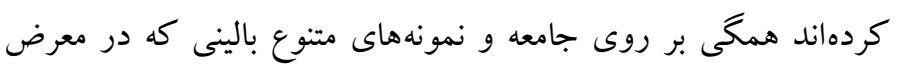

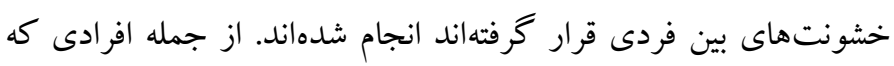

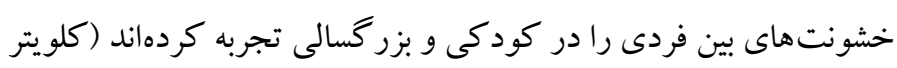

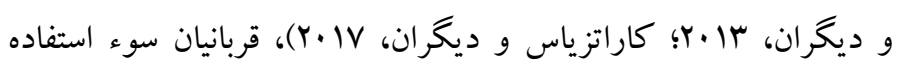
جنسى در كودكى (هايلند، شولين، الكليت، مورفى، والرى، كارورت،

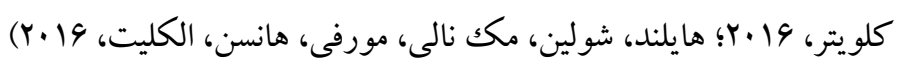
و نوجو انان حاضر در جنك هاى داخلى به عنوان سربازان اجبارى (دو كدال،

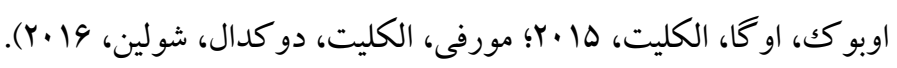

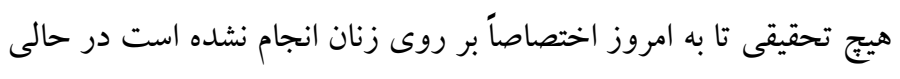

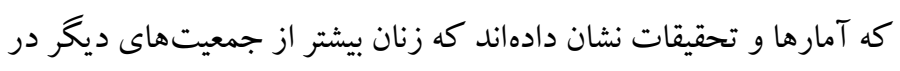

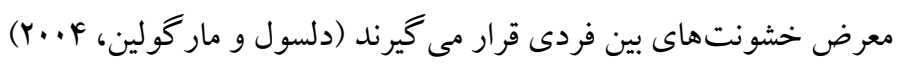

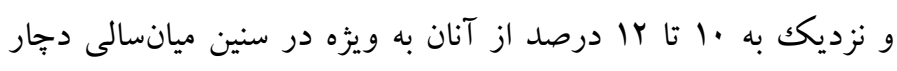
اختلالات مرتبط با تجارب آسيبزا از جمله PTSD مى شوند (ويليس، جو تو نو

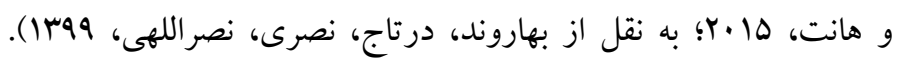

\footnotetext{
${ }^{6}$. Sense of threat

7 . Disturbances in self-organization

${ }^{8}$. Affective Dysregulation

9 . Negative Self-Concept

${ }^{10}$. Disturbances in Relationships
}

مقلفمه

در نسخه يازدهم سازمان جهانى بهداشت از طبقهبندى بين المللى بيمارى

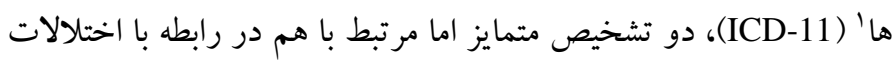

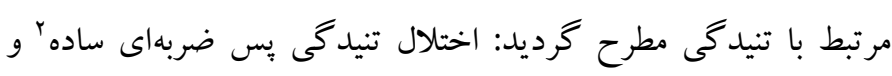

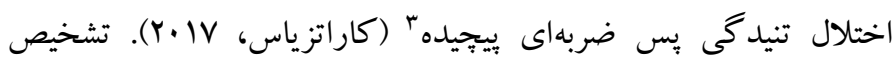

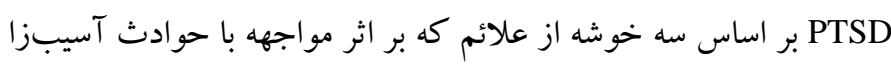

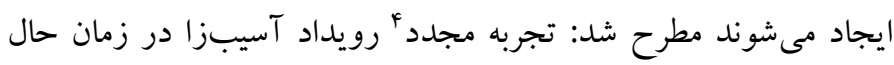

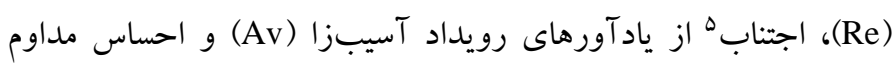

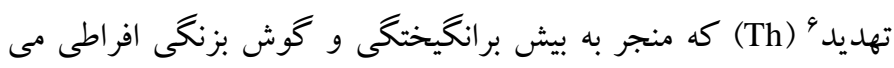

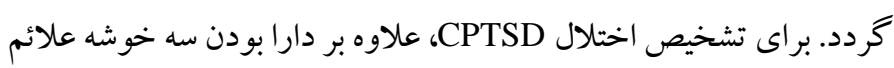

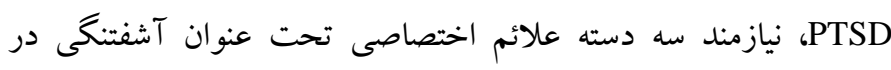

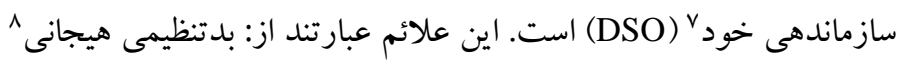

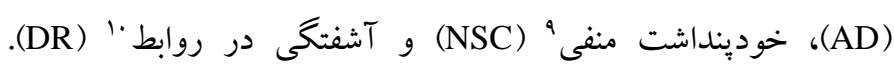
تحقيقات مختلف عنوان كردهاند كه اختلال CPTSD بر اثر مواجهه با دودئل رويدادهاى آسيبزاى شديد، تكرار شونده و مزمن در دوران اوليه تحول

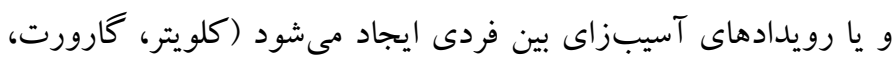

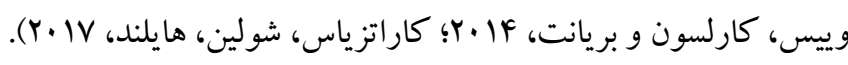
يرسشنامه بين المللى رويدادهاى آسيبزا (ITQ) براى تعيين اعتبار سازه اختلال PTSD و CPTSD بر اساس معيارهاى تشخيصى

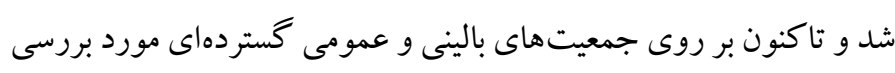

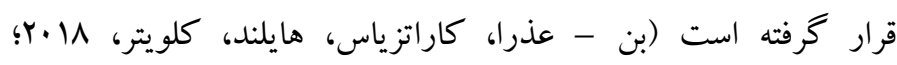

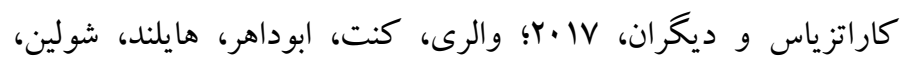

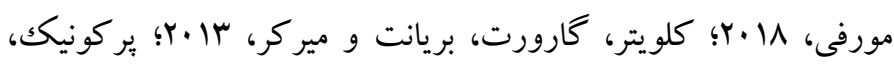

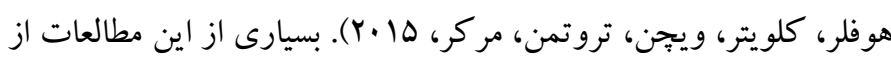
درستى سازه اختلال PTSD و CPTSD به عنوان دو طبقه تشخيصى مجزا آنكونه كه در ICD-11 مطرح شده است، حمايت كردهاند (كلوتر،

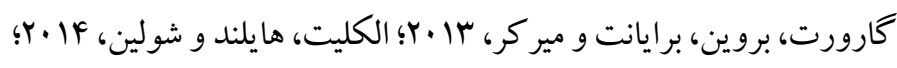

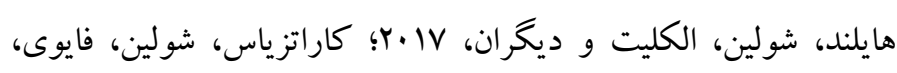

${ }^{1}$. International Classification of Diseases (ICD)

2. Posttraumatic Stress Disorder (PTSD)

${ }^{3}$. Complex Posttraumatic Stress Disorder (CPTSD)

4. Reexperiencing

5. Avoidance 
گر دد. پِ إز آمادهسازى نسخه فارسى يرسشنامه بين المللى رويدادهاى

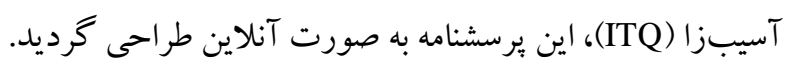

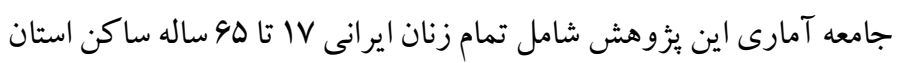
تهران بودند كه به دليل شيوع ويروس كرونا و محدوديت هاى موجودة،

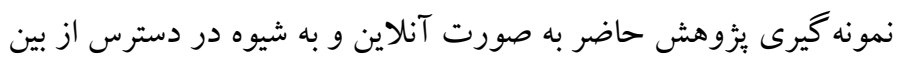

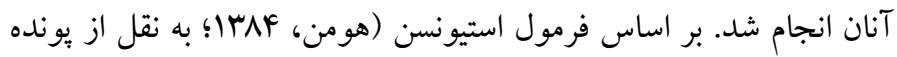

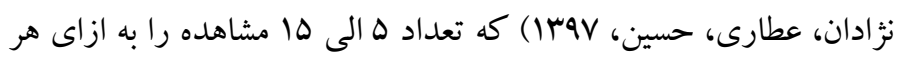

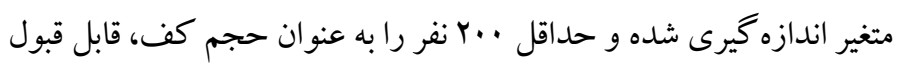

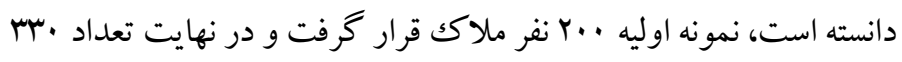

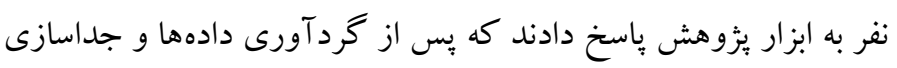

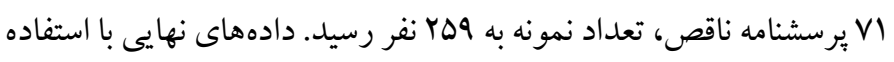

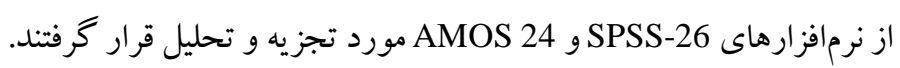

ب) ب ابز ار برسشنامه بين المللى رويدادهاى آسيبزا (ITQ): ير سشنامه بين المللى وقايع

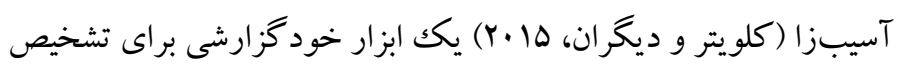

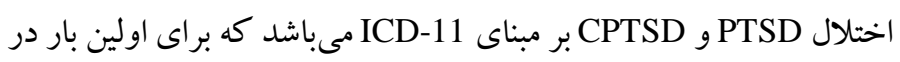

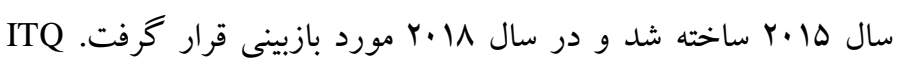
بريشان كنندهترين رويدادهاى آسيبزا و مدت زمانى كه از اين وقايع

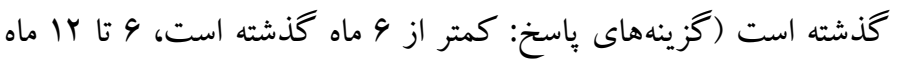

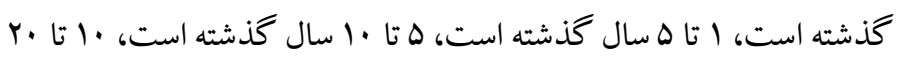

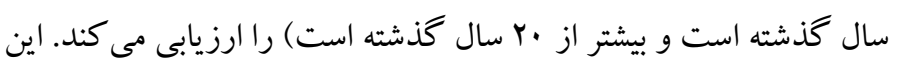

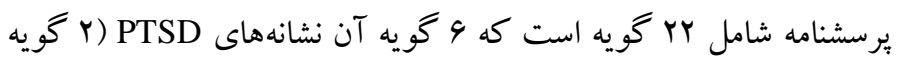

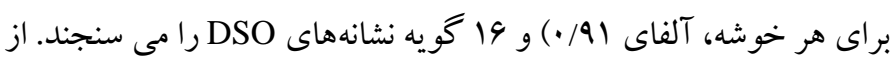

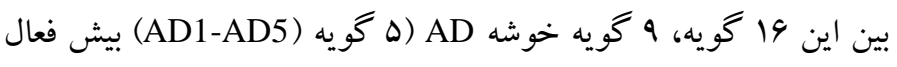

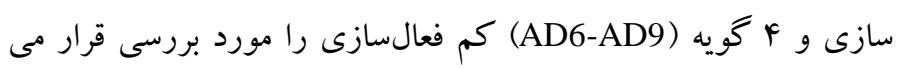

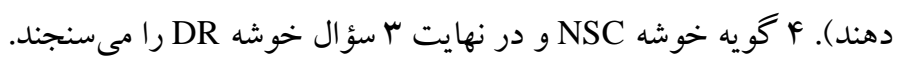

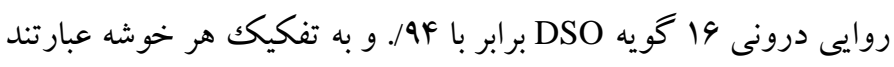

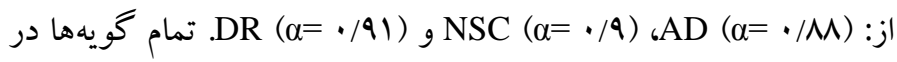

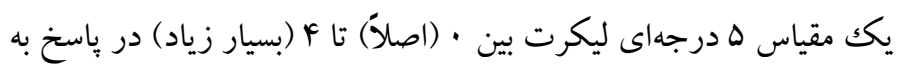

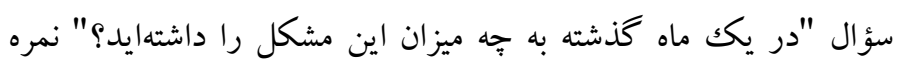

3. Confirmatory Factor Analysis (CFA)
همجنين لازم به ذكر است در اكثر تحقيقاتى كه تاكنون صورت گرفته، بدتنظيمى هيجانى (AD) به عنوان يك ساختار واحد در نظر كرفته شده

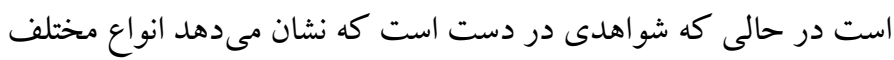
بدتنظيمى هيجانى با انواع مختلف سوء استفاده در دور ان كود كىى در ارتباط

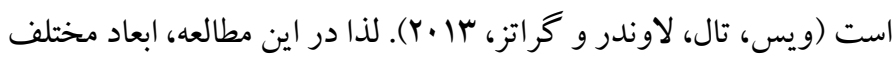

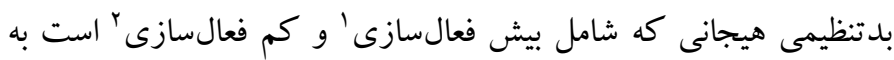
عنوان عوامل مجز ا مورد بررسى قرار مى گئيرند.

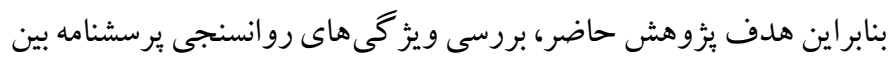

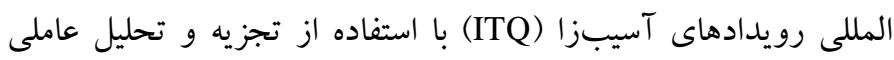
تأييدى (CFA) و همجنين ارزيابى دامنههاى AD (بيش فعالسازى و كم

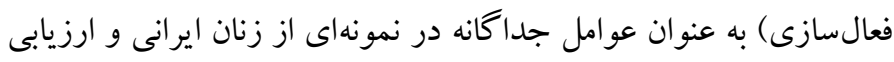

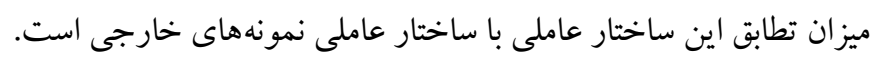

روش الف) طرح هئوهش و شر كت كنند كان: روش يثزوهش حاضر، توصيفى

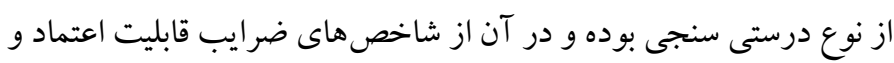

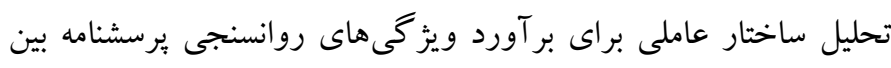

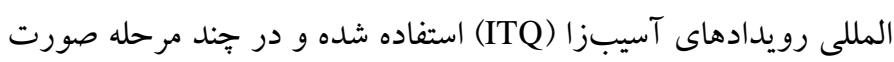
كرفته است: - ملتى

بر طبق دستور العمل هاى موجود براى انطباق بين فرهنگى ابزارها، معمولاً

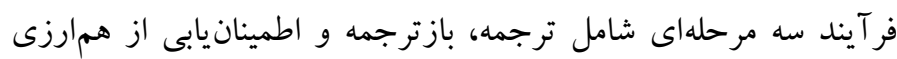

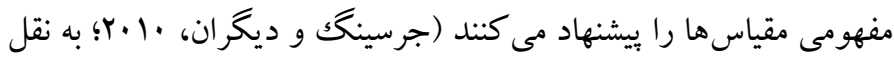

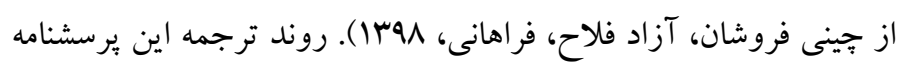

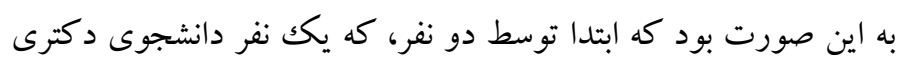

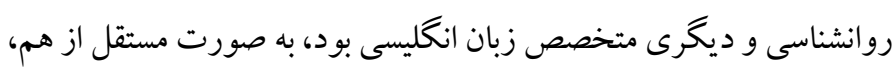

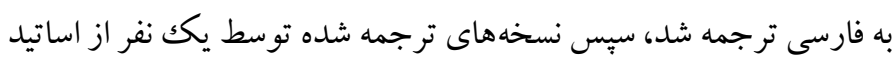

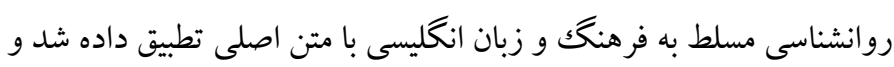

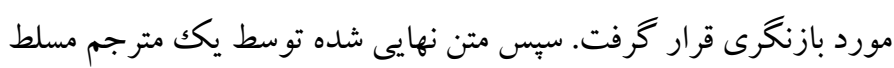

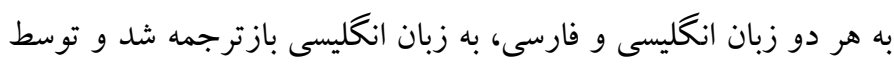

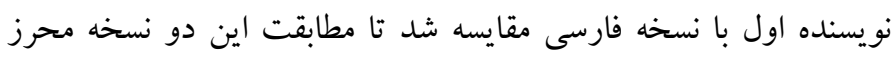

1 . Hyper- activation

2 . Hypo- activation 


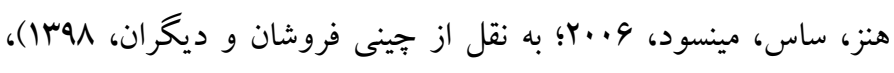

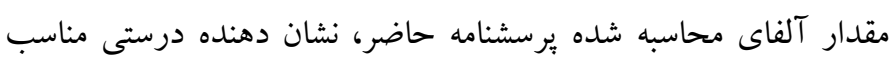

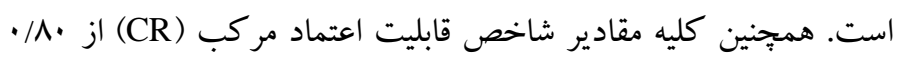

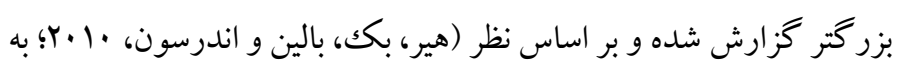

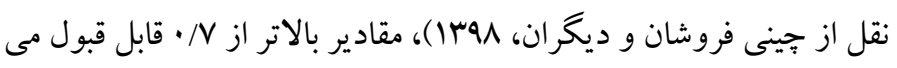
باشند.

جدول ا. آلفاى كرونباخ و ضريب قابليت اعتماد مركب (CR) يرسشنامه بينالملى

\begin{tabular}{|c|c|c|}
\hline قابليت اعتماد مركب & آلفاى كرونباخ & عامل \\
\hline$\cdot / \mathrm{AV}$ & - /Ar & PTSD \\
\hline . /149 & $\cdot|A|$ & DSO \\
\hline
\end{tabular}

در ادامه با استفاده از روش تحليل عاملى تأييدى به بررسى درستى “ّازه

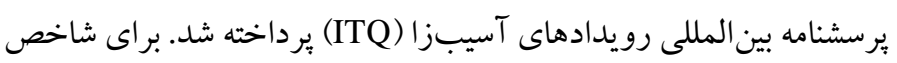
هاى برازندگى برش هاى متعددى توسط متخصصان مطرح شده است. بر ايى

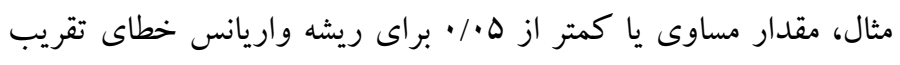

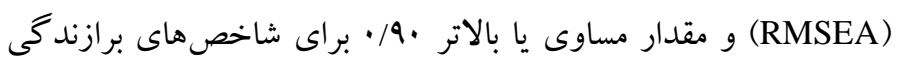

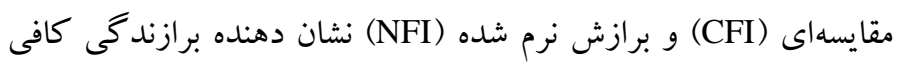

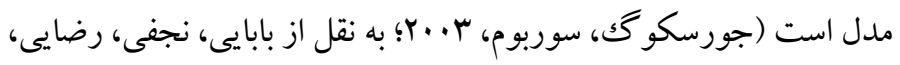

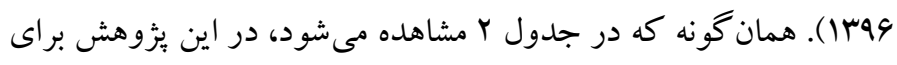
بررسى برازش مدل به دست آمده، از شاخصهاى مجذور خى، خى دو

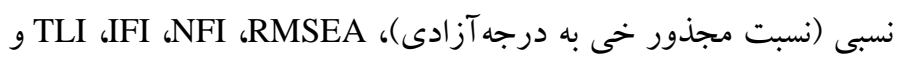

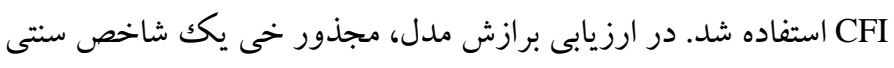

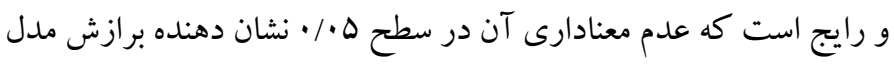
بسيار مناسب مدل است، با اين حال اين شاخصها با محدوديتهاى قابل

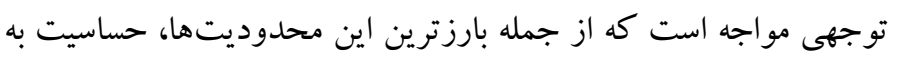

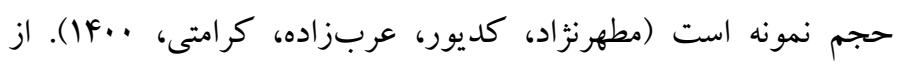
آنجايى كه مجذور خیى در اصل يكك آزمون معنادارى آمارى است، كاربرد

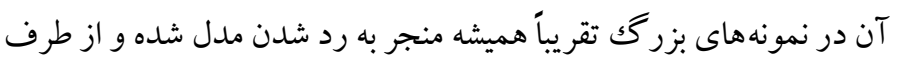

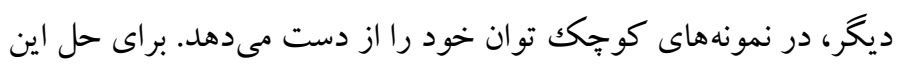
مشكل و كاهش اثر حجم نمونه، شاخص نسبت مجذور خیى دو بر درجه

\section{3 . Validity}

كذارى مى گردند. براى تشخيص PTSD فرد بايد در هر يكك از خوشهها نمره مساوى يا بالاتر از Y كسب نمايد. براى تشخيص (Th Av، Re) نPTSD

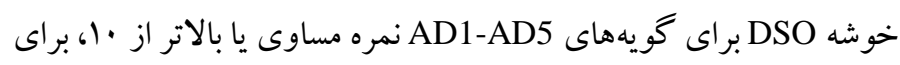
AD6-AD9 Aو براى گويههاى DR نمره مساوى يا بالاتر از 4 كسب نمايد.

يافته ها يثزوهش حاضر بر روى يكك نمونه به نفرى از زنان عادى اجرا شد. در

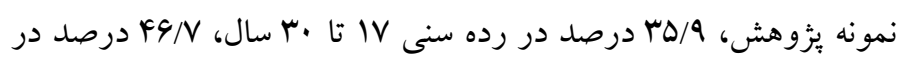

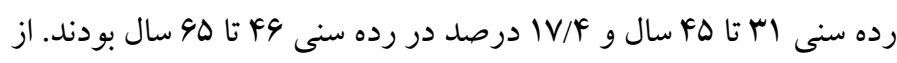

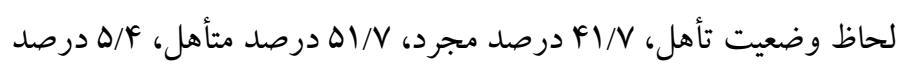

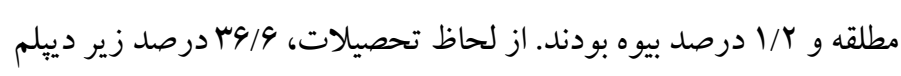

و دييلم، FV/I درصد ليسانس و 19/9 درصد فوق ليسانس و بالاتر بوند. قبل از انجام تحليل هاى آمارى، آزمونهاى مقدماتى بر ایى بررسى دادههاى

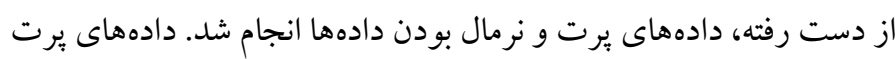

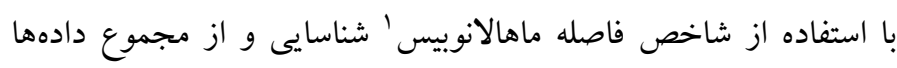

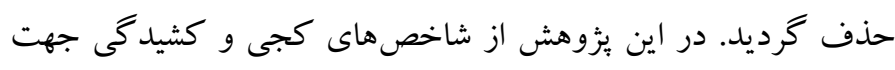

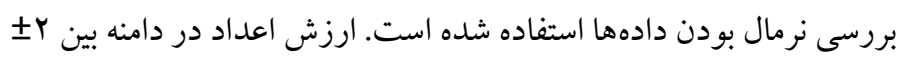

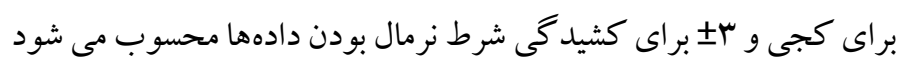

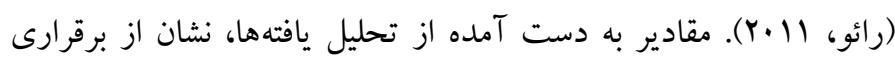
مفروضه نرمال بودن دادههاى حاصل از ابزار بززوهش براى تمامى كويهها دارد.

ابتدا براى تعيين قابليت اعتماد يرسشنامه از آلفاى كرونباخ استفاده شد و

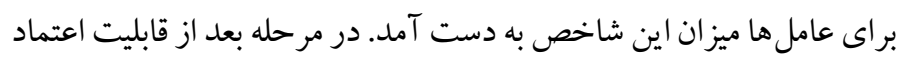

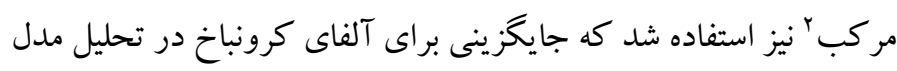

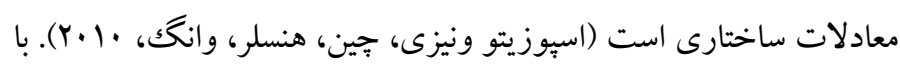
توجه به نتايج به دست آمده در جدول (، ضريب آلفاى كرونباخ براى عامل

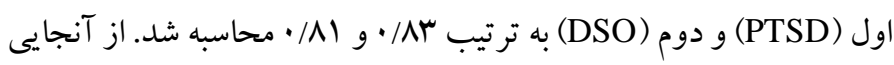
كه مقدار مناسب آلفا براى اعتبار يكك مقياس بزر گك تر از N/ • است (هلمز،

1. Mahalanobis

${ }^{2}$. Composite Reliability; CR 
شاخص هاى نيكويى برازش كه عبارتند از CFI و TLI IIFI،NFI، مقاديرى بين صفر تا يكك را مى تواند استفاده كنند كه هر جه مقدار آنها به يك رسك نزديككتر باشد، مدل از برازش بهترى برخوردار است. اين مقادير در

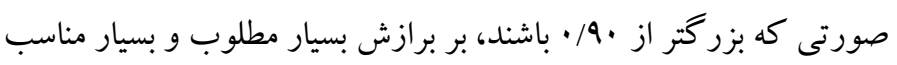

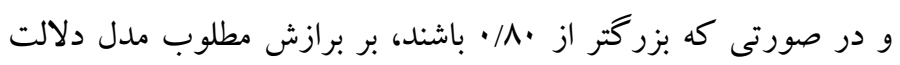

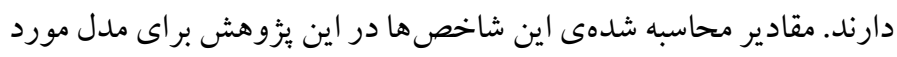

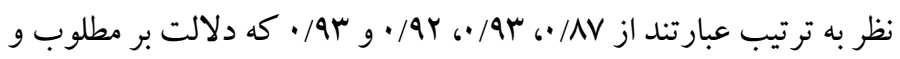
بسيار مطلوب بودن مدل به دست آمده دارند.

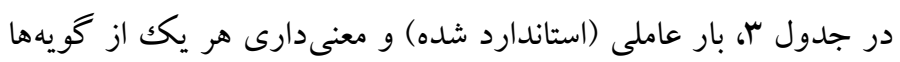
كزارش شده است. با توجه به جدول با، كليه بارهاى عاملى داراى تفاوت معنى دار در سطح خطاى بحر انى و استاندارد هـ • • مىباشند.
آزادى معرفى شد. اخر جٍه خى دوى نسبى فاقد يكك مقدار ثابت به عنوان

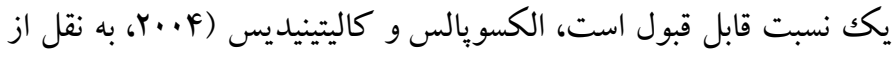

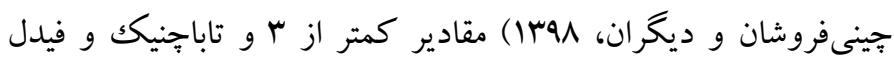

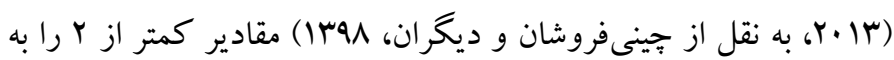
عنوان نسبت قابل قبول براى اين شاخص جهت برازش بسيار مطلوب مدل

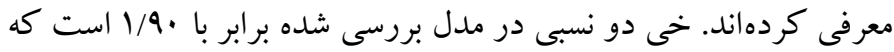

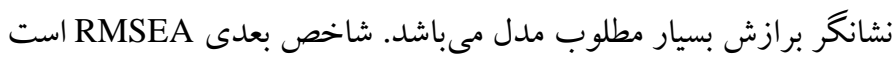

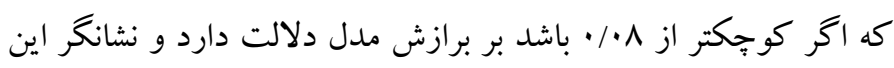

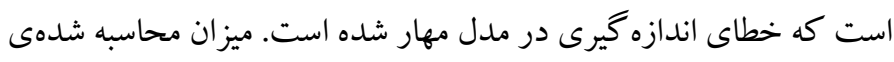

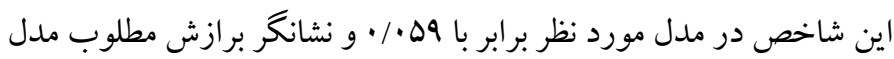
به دست آمدهى يزوهش حاضر است. ساير شاخص هاى محاسبه شده از

جدول r. شاخصهاى نيكويى برازش مدل دو عاملى يرسشنامه بين المللى رويدادهاى آسيبزا

\begin{tabular}{|c|c|c|c|c|c|c|c|c|}
\hline RMSEA & NFI & IFI & TLI & $\mathrm{CFI}$ & $\mathrm{X}^{2} / \mathrm{df}$ & $\mathrm{P}$ & df & $\mathrm{X}^{2} \square$ \\
\hline.$/ \Delta q$ & $\cdot / A V$ & . & . /Ar & . & $1 / 9$. & $\cdot / \cdots 1$ & $r .$. & $r \Lambda \cdot / F r V$ \\
\hline
\end{tabular}

جدول ". بار عاملى و معنى ارارى هر يك از كويه هاى يرسشنامه بين المللى رويدادهاى آسيبزا

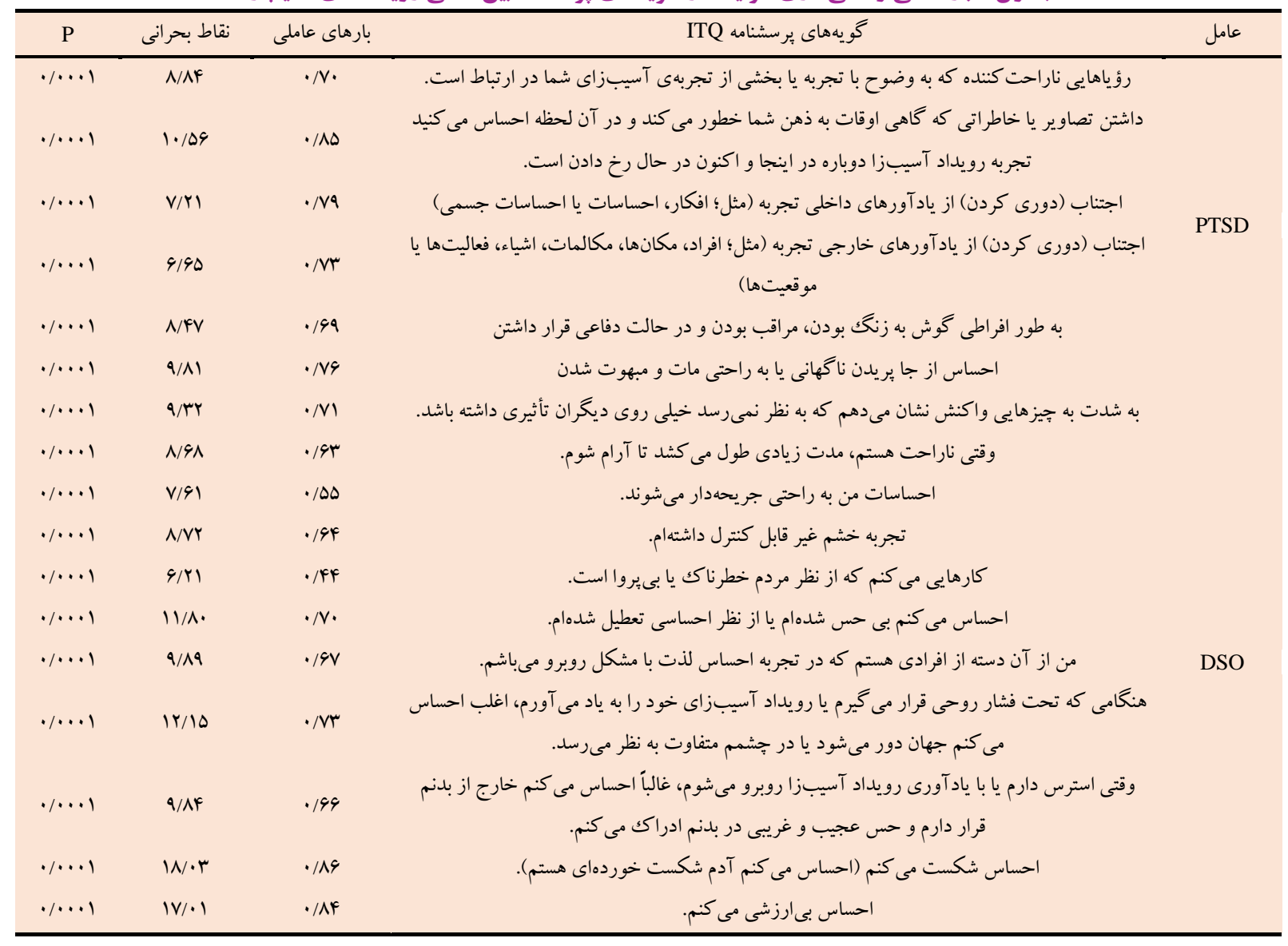




\begin{tabular}{|c|c|c|c|c|}
\hline $\bar{P}$ & نقاط بحر انى & بارهاى عاملى & كويههاى يرسشنامه ITQ & عامل \\
\hline$\cdot / \cdots+1$ & $|N / 1|$ & $\cdot / \mathrm{AV}$ & احساس مى كنم شرمنده خودم هستم؛ جه منطقى باشد جه نباشد. & \\
\hline$\cdot / \cdots \cdot 1$ & $19 / 01$ & . & نسبت به كارهايى كه انجام دادهام يا نتوانستهام انجام دهم احساس گكناه مى كنم. & \\
\hline$\cdot \cdots \cdot 1$ & $11 / 99$ & $\cdot / \mathrm{v} \wedge$ & احساس مى كنم از مردم دور هستم يا با آنها ارتباطم قطع شده است. & \\
\hline$\cdot / \cdots \cdot$ & $\mid r / \Delta \Lambda$ & . $/$ Ar & براى من سخت است كه از نظر عاطفى - احساسى به مردم نزديكك بمانم. & \\
\hline$\cdot / \cdots 1$ & $11 / \cdot 1$ & $\cdot / \mathrm{NI}$ & از روابط اجتناب مى كنم زيرا در نهايت آنها بسيار سخت يا دردناكك خواهند بود. & \\
\hline
\end{tabular}

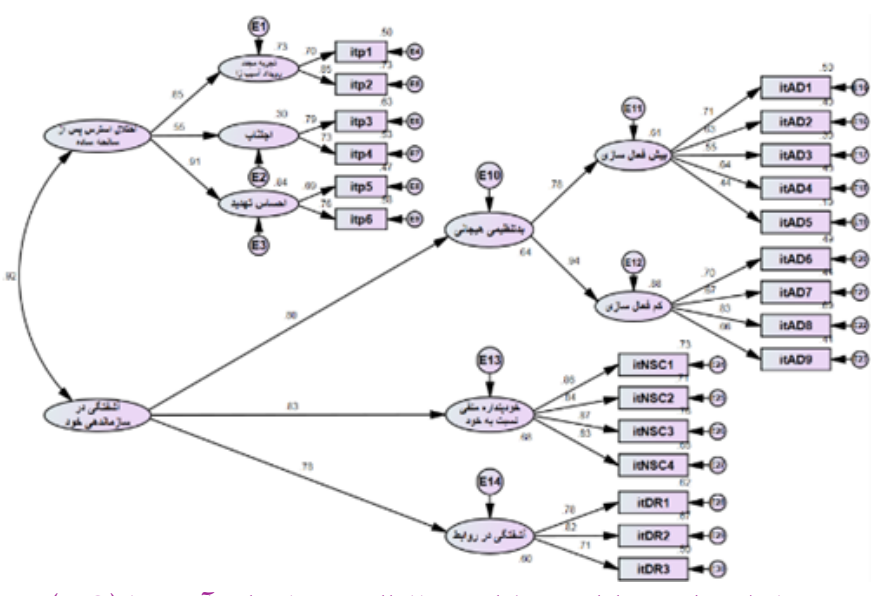

نمودار ا. مدل دو عاملى يرسشنامه بينالمللى رويدادهاى آسيبزا (ITQ) و ضرايب استاندارد مسيرها

\section{بحث و نتيجه تيرى}

همانطور كه بيشتر عنوان شد، يُزوهش حاضر به به منظور اولين ارزيابى از اعتبار ساختارى يرسشنامه بين المللى رويدادهاى آسيبزا (ITQ) در ميان

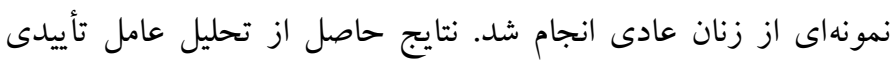
(CFA)

$$
\text { معيارهاى تشخيصى ICD-11 فراهم كرد. }
$$

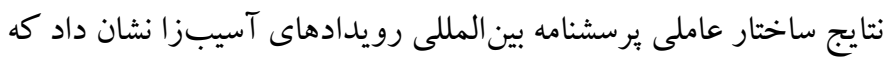
كل مادههاى يرسشنامه ITQ به طور معنادارى روى عامل مربوط به خود ئرس

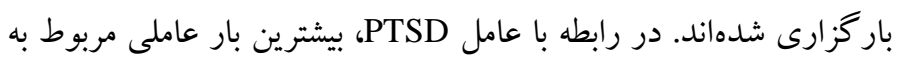
مادهى P2 "داشتن تصاوير يا خاطر اتى كه گاهى اوقات به ذهن شما خطور مى كند و در آن لحظه احساس مى كنيد تجربه رويداد آسيبزا دوباره در اينجا و اكنون در حال رخ دادن است" با بار عاملى هـ/· و كمترين بار

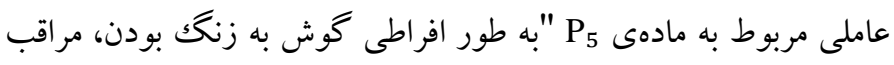

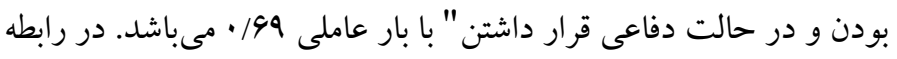
با عامل DSO نيز بيشترين بار عاملى مربوط به مادهى NSC

2. Average Variance Extracted; AVE
همجنين اكر همبستكى بين نمرات آزمونهايى كه خصيصه واحدى را

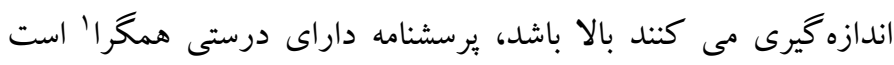

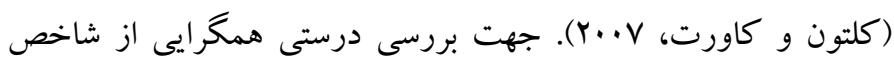

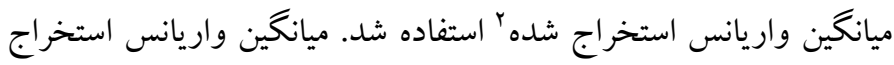

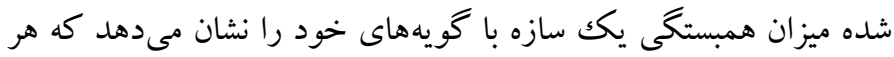

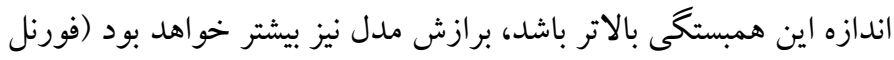

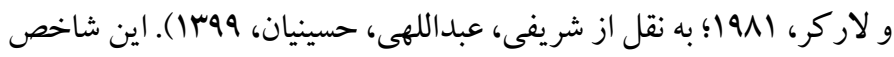

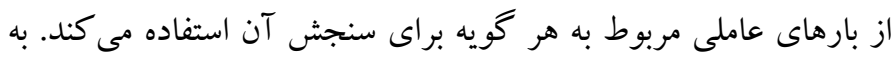

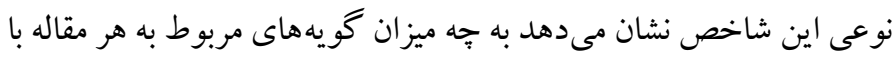
يكديگر از همبستخى كافى و بالايى برخوردار هستند (هنسلر، رينگل،

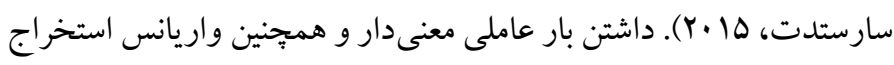

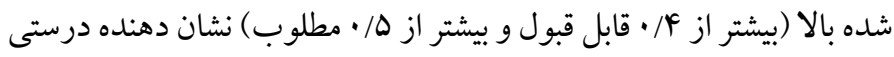

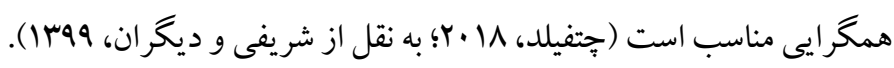
جدول ع. ميانكين واريانس استخراج شده (AVE) عاملهاى برسشنامه بينالمللى

\begin{tabular}{|c|c|}
\hline \multicolumn{2}{|c|}{ رويدادهاى آسيبزا } \\
\hline AVE & 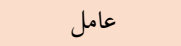 \\
\hline .190 & عامل اول: PTSD \\
\hline .194 & عامل دوم: SDO \\
\hline
\end{tabular}

همان گونه كه نتايج جدول \& نشان مىدهد، يرسشنامه بين الملى رويدادهاى

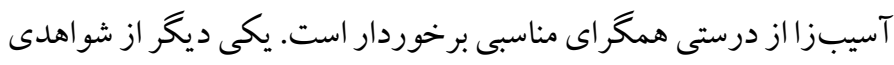

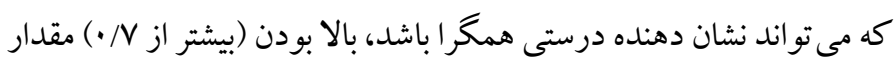
قابليت اعتماد مركب كل برسشنامه است. همجينين مقدار قابليت اعتماد

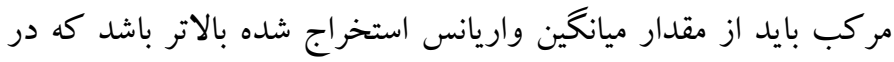

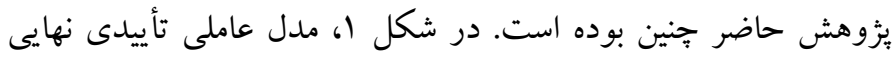

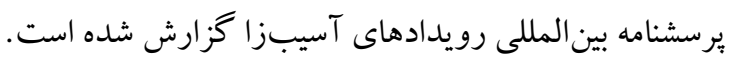

\footnotetext{
1. Convergent validity
} 
اين مدل در ميان نمونهاى از زنان ايرانى ارائه داده و نشان مىدهد كه

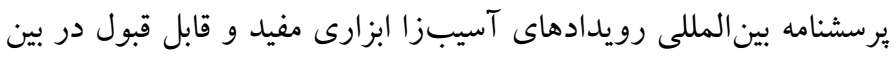

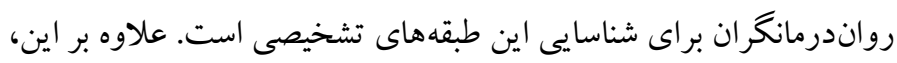

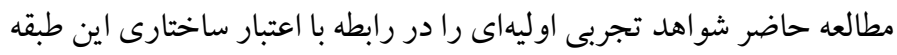

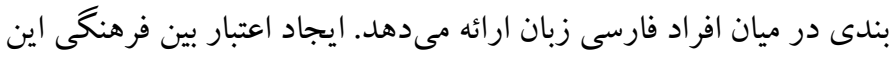
اختلالات با توجه به تأكيد سازمان جهانى بهداشت (WHO) به اين امر كه ترسك

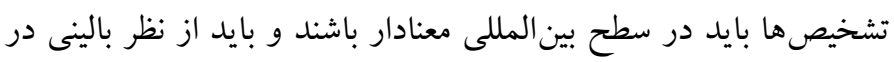
زمينه هاى بشردوستانه ارائه شوند، ضرورى است

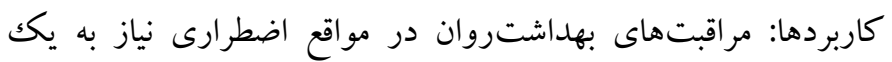

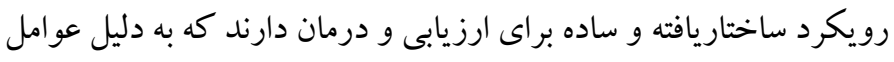

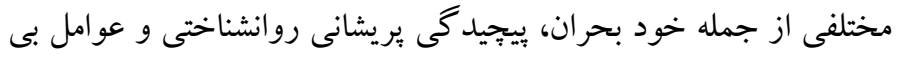

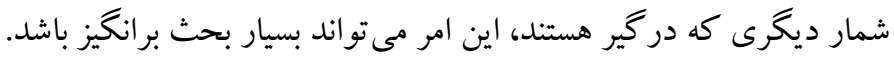

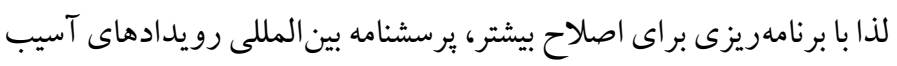

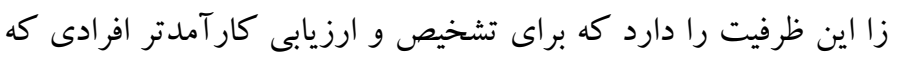
دجار بريشانىهاى روانشناختى مرتبط با رويدادهاى آسيبزا شدهاند،

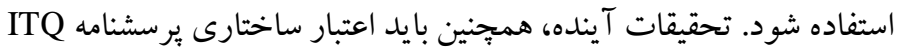
را در ميان ساير جمعيتها از جمله كودكان و نوجوانان كه از آسيب

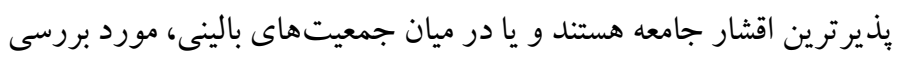

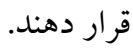

محدوديتها: يافتهاى مطالعه حاضر بايد در رابطه با جندين محدوديت

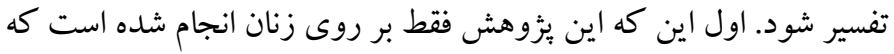
اين مسأله قابليت تعميميذيرى يافتها را محدود مى سازد، بنابر اين بيشنهاد مىشود كه نتايج يزوهش حاضر در جامعه مردان نيز مورد بررسى قرار

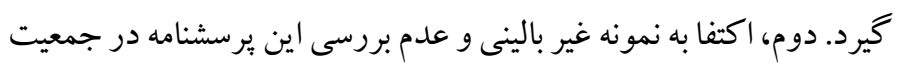

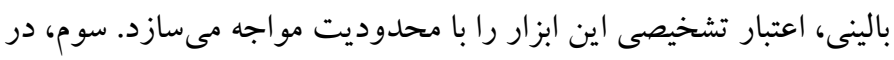
اين يزوهش تنها از آلفاى كرونباخ براى بررسى قابليت اعتماد استفاده شد.

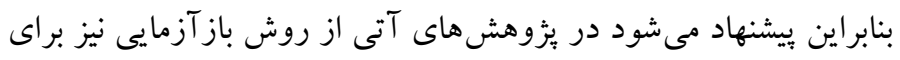

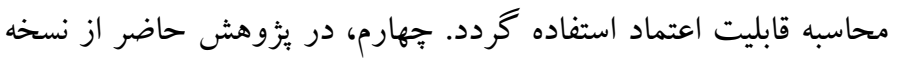
اصلى Y Y گويهاى برسشنامه بين المللى رويدادهاى آسيبزا استفاده شده

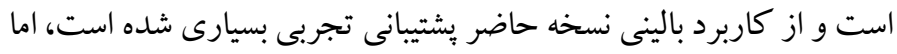
در تحقيقات جديد تعداد علائم DSO از 19 به 9 كاهش يافته است.

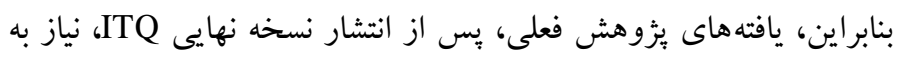

كنم شرمنده خودم هستم؛ جهه منطقى باشد جه نباشد" با بار عاملى AV/· و و

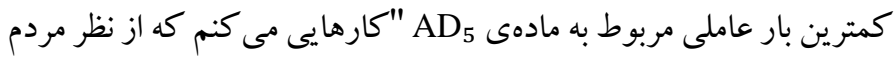

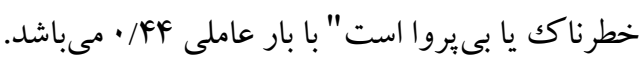

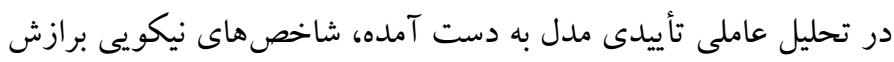

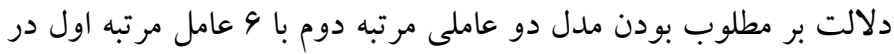

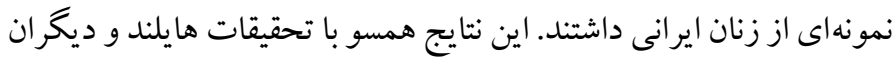

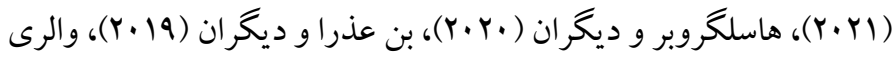

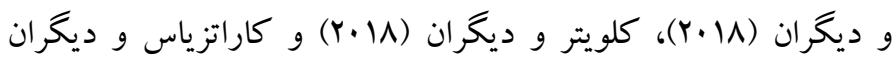
(Y. (Y IV) در بررسى اعتبار مقياس نيز، در يزوهش حاضر ضريب آلفاى كرونباخ در

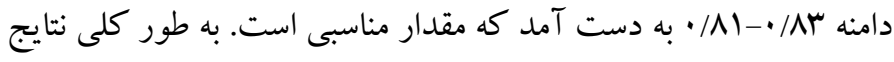
نشان مىدهد نسخه فارسى يرسشنامه بين المللى رويدادهاى آسيبزا (ITQ) براى تشخيص و تمايز اختلال PTSD و CPTSD در زنان ايرانى درستى و قابليت اعتماد مناسب را دارد. مطالعه حاضر علاوه بر بررسى كلى ساختار عاملى يرسشنامه بينالمللى

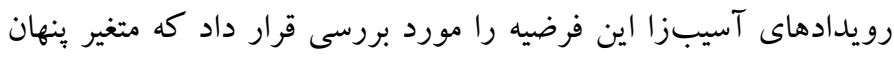
بدتنظيمى هيجانى ممكن است توسط دو عامل كه "بيش فعالساز" و "كم

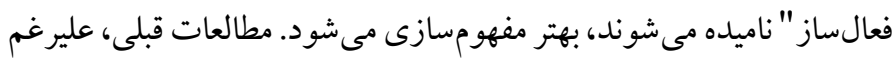

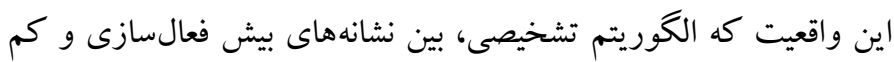

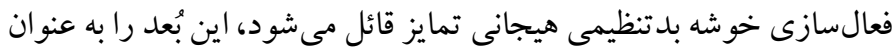

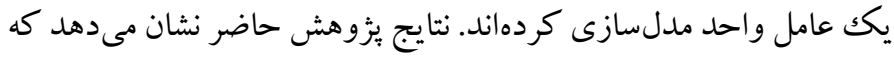
تشخيص متمايز از نشانهاى بدتنظيمى هيجانى به ايجاد مدل مناسبترى ترى

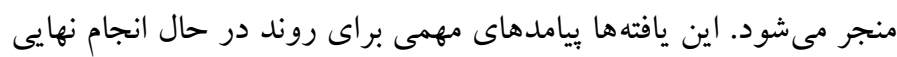

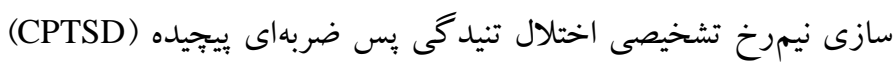

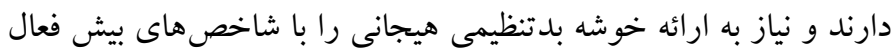
سازى و كم فعالسازى، برجسته مىسازد.

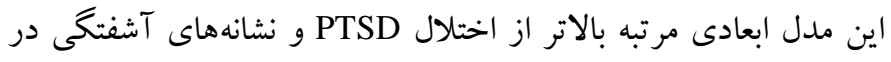

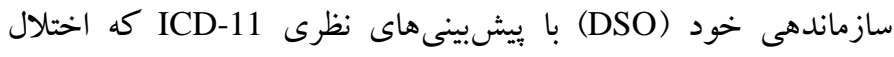
را توسط اين دو مجموعه از علائم توصيف كرده است، مطابقت لعTSD

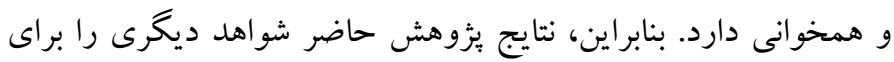

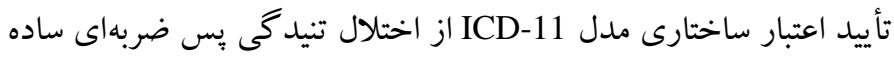

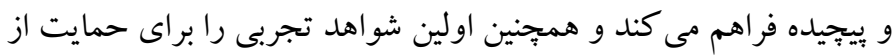




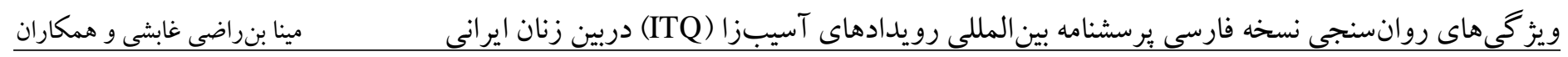

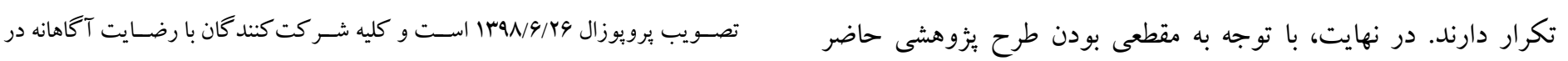

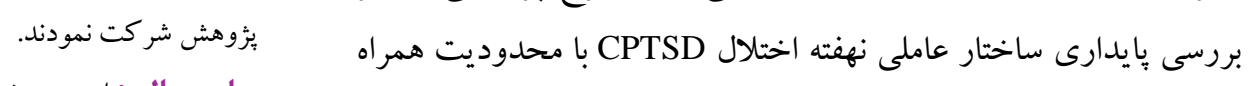
حامى مالى: اين يُزوهش در قالب رساله دكترى و بدون حمايت مالى مئاشد.

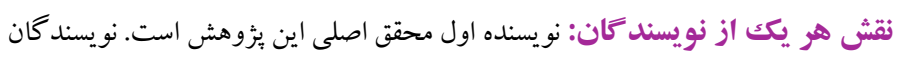

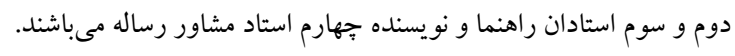

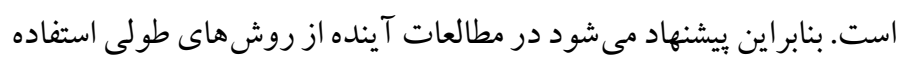
شود تا بايدارى ابعاد نهفته اين اختلال در طول زمان بروسى شود شود.

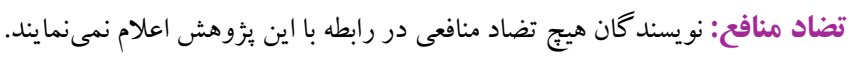

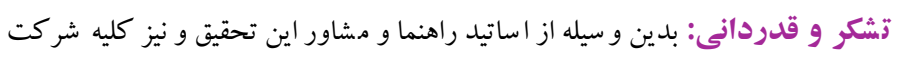
كند كان در اين يزوهش تشكر و قدردانى مى بر بردد.

ملاحضات اخلاقى يبيروى از اصول اخلاق بثروهش: اين مقاله بركرفته از رساله دكترى نويسنده اول در

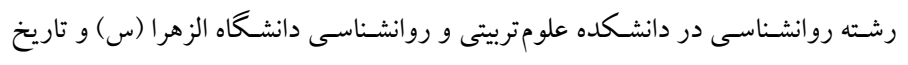




\section{References}

Babaee J, Najafi M, Rezaei A. (2018). The Psychometric Properties of Positive Youth Development Scale in Students. Journal of psychological science, 16(64), 540-553. (Persian). [Link]

Baharvand V, Dortaj F, Nasri S, Nasrollahi B. (2020). Comparison of the effectiveness of cognitive behavioral therapy with cognitive hypnotherapy and eye movement desensitization (EMDR) and reprocessing on the reduction of traumatic stress symptoms of flooded women. Journal of psychological science, 19(86), 203-212. (Persian). [Link]

Ben-Ezra, M., Karatzias, T., Hyland, P., Brewin, C., \& Cloitre, M. (2018). Posttraumatic stress disorder (PTSD) and complex PTSD (CPTSD) as per ICD11 proposal: A population study in Israel. Journal of Depression \& Anxiety, 35, 185-282. [Link]

Cloitre, M., Garvert, D. W., Brewin, C. R., Bryant, R. A., \& Maercker, A. (2013). Evidence for proposed ICD-11 PTSD and complex PTSD: A latent profile analysis. European Journal of Psychotraumatology, 4(1), 20706. DOI: 10.3402/ejpt.v4i0.20706. [Link]

Cloitre, M., Garvert, D. W., Weiss, B., Carlson, E. B., \& Bryant, R. A. (2014). Distinguishing PTSD, complex PTSD, and borderline personality disorder: A latent class analysis. European Journal of Psychotraumatology, 5, 1-8. [Link]

Delsol, C., \& Margolin, G. (2004). The role of family-oforigin violence in men's marital violence perpetration. Clinical Psychology Review, 24(1), 99-122. [Link]

Dokkedahl, S., Oboke, H., Ovuga, E., \& Elklit, A. (2015). ICD-11 trauma questionnaires for PTSD and complex PTSD: Validation among civilians and former abducted children in northern Uganda. Journal of Psychiatry, 18(335), 1-9. [Link]

Elklit, A., Hyland, P., \& Shevlin, M. (2014). Evidence of symptom profiles consistent with posttraumatic stress disorder and complex posttraumatic stress disorder in different trauma samples. European Journal of Psychotraumatology, 5 (1), 24221. DOI: 10.3402/ejpt.v5.24221. [Link]

Haselgruber, A., Solva, K., \& Lueger-Schuster, B. (2020). Symptom structure of ICD-11 Complex Posttraumatic Stress Disorder (CPTSD) in traumaexposed foster children: examining the International Trauma Questionnaire - Child and Adolescent Version (ITQ-CA). European Journal of Psychotraumatology, 11(1). [Link]
Henseler, J., Ringle, C. M., \& Sarstedt, M. (2015). A new criterion for assessing discriminant validity in variance-based structural equation modeling. Journal of the academy of marketing science, 43(1), 115-135. [Link]

Hyland, P., Murphy, J., Shevlin, M., Vallières, F., McElroy, E., Elklit, A., \& Cloitre, M. (2017). Variation in post-traumatic response: The role of trauma type in predicting ICD-11 PTSD and CPTSD symptoms. Social Psychiatry and Psychiatric Epidemiology, 6, 1-10. [Link]

Hyland, P., Shevlin, M., Elklit, A., Murphy, J., Vallières, F., Garvert, D. W., \& Cloitre, M. (2016). An assessment of the construct validity of the ICD-11 proposal for complex posttraumatic stress disorder. Psychological Trauma: Theory Research Practice and Policy, 9(1), 1-9. [Link]

Hyland, P., Shevlin, M., McNally, S., Murphy, J., Hansen, M., \& Elklit, A. (2016). Exploring differences between the ICD-11 and DSM-5 models of PTSD: Does it matter which model is used? Journal of Anxiety Disorders, 37, 48-53. [Link]

Karatzias, T., Shevlin, M., Fyvie, C., Hyland, P., Efthymiadou, E., Wilson, D., \& Cloitre, M. (2016). An initial psychometric assessment of an ICD-11 based measure of PTSD and complex PTSD (ICDTQ): Evidence of construct validity. Journal of Anxiety Disorders, 44, 73-79. [Link]

Motaharnejad E, Kadivar P, Arabzade M, Keramati H. (2021). Investigating of factor structure, validity and reliability of the Effortful Control Scale (ECS) in Iranian adolescents. Journal of psychological science, 20(102), 819-830. (Persian). [Link]

Murphy, S., Elklit, A., Dokkedahl, S., \& Shevlin, M. (2016). Testing the validity of the proposed ICD-11 PTSD and complex PTSD criteria using a sample from Northern Uganda. European Journal of Psychotraumatology, 7, 1-10. [Link]

Nickerson, A., Cloitre M, Bryant RA, Schnyder U, Morina N, Schick M (2016). The factor structure of complex posttraumatic stress disorder in traumatized refugees. European Journal of Psychotraumatology, 7(10), 33253. DOI: 10.3402/ejpt.v7.33253. [Link]

Perkonigg, A., Höfler, M., Cloitre, M., Wittchen, H. U., Trautmann, S., \& Maercker, A. (2015). Evidence for two different ICD-11 posttraumatic stress disorders in a community sample of adolescents and young adults. European Archives of Psychiatry and Clinical Neuroscience, 266(4), 317-328. [Link]

Pondeh Nezhadan AK, Attari Y, Hussein D. (2018). 
ويزگى هاى روانسنجى نسخه فارسى يرسشنامه بين المللى رويدادهاى آسيبزا (ITQ) دربين زنان ايرانى مينا بنراضى غابشى و همكاران

Factorial Structure and Reliability of Eating Mindfully Questionnaire (EMQ) among Married Women with Overweight and Obesity. Journal of Jundishapur Medical Sciences, 17(2), 131-143. (Persian). [Link]

Redican, E., Nolan, E., Hyland, P., Cloitre, M., McBride, O., Karatzias, T., Murphy, J., \& Shevlin, M. (2021). A systematic literature review of factor analytic and mixture models of ICD-11 PTSD and CPTSD using the International Trauma Questionnaire. Journal of Anxiety Disorders, 79. [Link]

Ryu, E. (2011). Effects of skewness and kurtosis on normal-theory based maximum likelihood test statistic in multilevel structural equation modeling. Behavior research methods, 43(4), 1066-1074. [Link]

Sharifi G, Abdollahi A, Hosseinian S. (2021). Psychometric Properties of the Persian Version of Personality Style and Disorder Inventory (PSDI-S) in Iranian Students. Rooyesh, 9(12), 43-54. (Persian). [Link]

Shevlin, M., Hyland, P., Karatzias, T., Fyvie, C., Roberts, N., Bisson, J. I., \& Cloitre, M. (2017). Alternative models of disorders of traumatic stress based on the new ICD-11 proposals. Acta Psychiatrica Scandinavica, 135(5), 419-428. [Link]

Vallieres, F., Ceannt, R., Abou Daher, R., Hyland, P., Shevlin, M., \& Murphy, J (2018). ICD-11 PTSD and complex PTSD amongst Syrian refugees in Lebanon: the factor structure and the clinical utility of the International Trauma Questionnaire. Acta Psychiatrica Scandinavica, 138, 547-557. [Link]

Wolf, E. J., Miller, M. W., Kilpatrick, D., Resnick, H. S., Badour, C. L., Marx, B. P., \& Friedman, M. J. (2015). ICD-11 complex PTSD in US national and veteran samples: prevalence and structural associations with PTSD. Clinical Psychological Science, 3(2), 215-229. [Link] 